\title{
Mechanical and Fracture Surface Analysis of Higher Viscous Epoxy/Multiwalled Carbon Nanotube Nanocomposites Subjected to Flexural Loading
}

\author{
Aidy Ali, Risby M. Sohaimi and \\ Ahmad H. Muhammad Ismail \\ Additional information is available at the end of the chapter \\ http://dx.doi.org/10.5772/intechopen.75992
}

\begin{abstract}
This study experimentally characterizes the effect of multiwalled carbon nanotubes (MWNTs) reinforced to higher viscous aircraft thermoset polymer epoxy. The effects of MWNTs weight percentage ( $\mathrm{wt} \%$ ) to flexural and fracture toughness properties were investigated via Mode I fracture behaviour. This experiment found that the average increment in fracture toughness of 0.1 and $0.3 \mathrm{wt} \%$ MWNTs reinforced to epoxy is 62.7 and $31.8 \%$, respectively. However, shifting to a higher viscosity epoxy lead to some difficulties like to remove void formed in matrix and harder to achieve appropriate carbon nanotubes (CNTs) dispersion due to limited pot life and working time. Morphological study analysis on fracture surface using field emission scanning electron microscopic (FESEM) shows that the mechanical properties enhancement was attributed to crack pinning, crack path deflection and localized inelastic matrix deformation due to agglomerated CNTs. The study concluded that the key important to the extent the strength and fracture toughness is by finding the appropriate processing method to achieve adequate state of CNTs dispersion within the matrix.
\end{abstract}

Keywords: fracture, impact, carbon nanotube, nanocomposites

\section{Introduction}

Thermosetting polymers have been extensively used in aviation industry as a replacement for historic manufactured materials such as steel and aluminium due to the remarkable advantages in strength and stiffness properties. Today, the incorporation of composites has become a common practice in aircraft design and manufacturing [1-7]. In the next generation 
of aircraft, the use of polymer composites is expected to hit more than $50 \%$ of the overall aircraft's structures. This transformation was developed due to the desire of reducing costs and weight while not losing the strength and stiffness of the materials. However, polymer composites have deprived in fracture toughness compared to steel and aluminium, and this became an impediment to polymer composites to become the so-called dominant materials on aircraft structures. Over the years, tremendous efforts [1-13] have been conducted to alter epoxy system by adding either micron-sized soft (rubber or thermoplastic) or rigid (glass or ceramic) particles into the polymer matrix. These filler particles are then expected to provide extrinsic toughening mechanism through crack bridging, crack pinning, crack path deflection, localized inelastic matrix deformation and void nucleation [8].

In recent years, carbon nanotubes (CNTs) have attracted a great interest for nanoparticlereinforcing candidates instead of those particles on polymer matrices due to proven superior mechanical, electronic and thermal properties [9]. Number of researches has been conducted to ascertain the mechanical characteristic of these nanopolymer composites. Certain properties pertaining to the aircraft structural composite, which are flexural strength and fracture toughness, have become an important basic property to predict the life of the composite structure. In the works of evaluating the effect of CNTs incorporation to polymer epoxy's fracture toughness, Thostenson et al. [10] reported adding 0.1 and $2.0 \mathrm{wt} \%$ into epoxy resin shows an increase in fracture toughness from 0.66 to 0.73 and $0.84 \mathrm{MPa} . \mathrm{m}^{1 / 2}$, respectively. In the work of Yu et al. [11], the mode I fracture toughness of 1.0-3.0 wt \% of multiwalled carbon nanotubes (MWNTs) reinforced epoxy-matrix composites is experimentally determined via compact test, and it is in the range of $0.53-0.73 \mathrm{MPa}^{1 / 2}$. Other work by Zhou et al. [12] conducted flexural and fracture toughness tests and reported that the strength and fracture toughness of MWNTs reinforced epoxy are $120 \mathrm{MPa}$ and $150 \mathrm{MPa} \cdot \mathrm{mm}^{1 / 2}$, respectively, for $0.3 \mathrm{wt} \% \mathrm{MWNTs}$. These variations of results reported are due to the different types of epoxy system and nanocomposite processing techniques used.

Basically, CNTs improve high mechanical properties at low volume fractions due to the high aspect ratio to volume ratio of the nanosized particles. However, high specific ratio has a strong tendency to agglomerate and has an adverse effect that decreases the strength of the nanocomposite due to the stress concentration effect [12]. Thus, the significant enhancement in polymer-CNTs composites is generally dependent to the degree of dispersion and interfacial adhesion conditions between CNTs and matrix. Srivasta and Singh [13] and Gkikas et al. [14] reported that the strength and fracture toughness enhancement in 0.5 and $1.0 \mathrm{wt} \%$ MWNTs inclusion have a wide range of enhancement or detraction value, which is very sensitive to the dispersion technique applied. This study is an attempt to apply CNTs into the epoxy resin, Hysol EA956 A/B that has been practically used for modern aircrafts. The primary objective is to determine the effect of adding CNTs to strength and fracture toughness properties of epoxy, in which the viscosity is higher than any resin previously studied. The fracture behaviour and mechanisms of reinforced materials will be inspected using FESEM. FESEM is able to provide morphological evidence of CNTs in epoxy resin that helps to assess the dispersion of CNTs. 


\section{Materials and methods}

An industrial grade multiwalled carbon nanotubes (MWCNTs) produced by Timesnano, China with $>90 \%$ purity, outer diameter of $10-30 \mathrm{~nm}$ and length of $10-30 \mu \mathrm{m}$ were used in this experiment. The morphology of the product was inspected with Nova NanoSEM 240 (Figure 1). The Hysol EA956 A/B, an aviation grade epoxy system, obtained from Henkel Corporation Aerospace Group, USA. It is a two-component adhesive, Part A (epoxy resin) and Part B (hardener) with the viscosity of 35 Pa.S (Pascal-second @ kg/ms) and 2 Pa.S, respectively. The mix ratio is 100:58.

For the preparation of control samples ( $0 \%$ CNTs), neat resin specimen was prepared by mixing Part A epoxy resin and Part B hardener thoroughly. The slurry was then placed inside a vacuum container to remove the entrapped air for $20 \mathrm{~min}$ before transferring into a mould for further curing processes. For the CNT-based polymer composites, MWCNTs $(0.1 \%$ and $0.3 \%)$ were dispersed into Part B via ultrasonication process by Qsonica Q700 for 30 min at 10\% of power amplitude. After sonication, Part A epoxy resin was added to the CNT-Part B slurry and stirred for $10 \mathrm{~min}$ at $550 \mathrm{rpm}$ using a mechanical stirrer. Air bubbles were removed by placing the mixture inside a vacuum container for $20 \mathrm{~min}$.

Three samples were prepared for each sample types in according with ASTM 5045-99. After the samples cured and de-mould, $2 \mathrm{~mm}$ notch tip was generated mechanically using Ray-ran Motorspeed Notching Cutter. The tests were conducted in a $50 \mathrm{kN}$ Instron 5569A servo-hydraulic testing machine with crosshead speed of $1.0 \mathrm{~mm} / \mathrm{min}$. A crack opening displacement (COD) gauge was fixed to the samples to measure the initial fracture displacement during the testing. The morphology of MWNTs in epoxy was observed under field emission

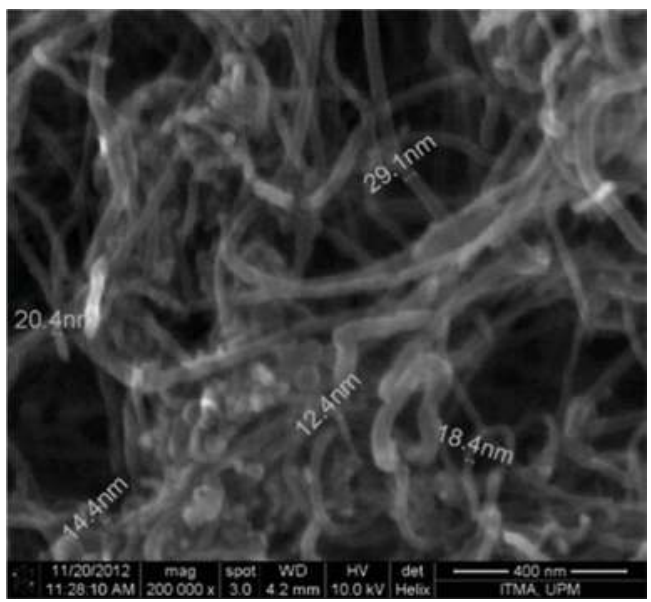

Figure 1. SEM picture of as received MWNTs. 
scanning electron microscopy (FESEM) using Nova NanoSEM 240. After mechanical test, all the sample fracture surfaces were coated with a thin gold layer by sputtering process to make them conductive for SEM analysis.

\section{Results and discussion}

Table 1 and Figure 2 show that by addition of MWNTs to epoxy system, the flexural strength of MWNT-based composites was found to exhibit non-linear behaviour with respect to MWNTs $w t \%$ inclusion. The optimal improvement was found at $0.1 \mathrm{wt} \%$ MWNTs, whereas a slight reduction was found at $0.3 \mathrm{wt} \%$ MWNTs. This trend was also observed for the flexural modulus but a significant reduction was observed at $0.3 \mathrm{wt} \%$ MWNTs content. The mode I fracture critical stress intensity factor $\left(\mathrm{K}_{\mathrm{IC}}\right)$ of the specimen is listed in Table 2. As shown in Figure 3, the fracture toughness of MWNTs reinforced epoxy was improved by $62.7 \%$ at $0.1 \mathrm{wt} \% \mathrm{CNTs}$ and $31.8 \%$ at $0.3 \mathrm{wt} \%$. This result showed a different trend compared to the works reported by Zhou et al. [12] using Epon 862 epoxy with viscosity 4.5 Pa.S, Li et al. [15] using Epoxy 828 with viscosity $15 \mathrm{~Pa} . \mathrm{S}$ and Gojny et al. [8] using L135i epoxy with viscosity $0.25 \mathrm{~Pa} . \mathrm{S}$ (Figure 3).

\begin{tabular}{lll}
\hline CNT weight percentage (\%) & Flexural Strength (Mpa) & Modulus (Mpa) \\
\hline 0.0 & 14.659 & 917.058 \\
0.1 & 23.783 & 952.441 \\
0.3 & 19.273 & 857.787 \\
\hline
\end{tabular}

Table 1. Flexural strength and modulus properties of epoxy system.

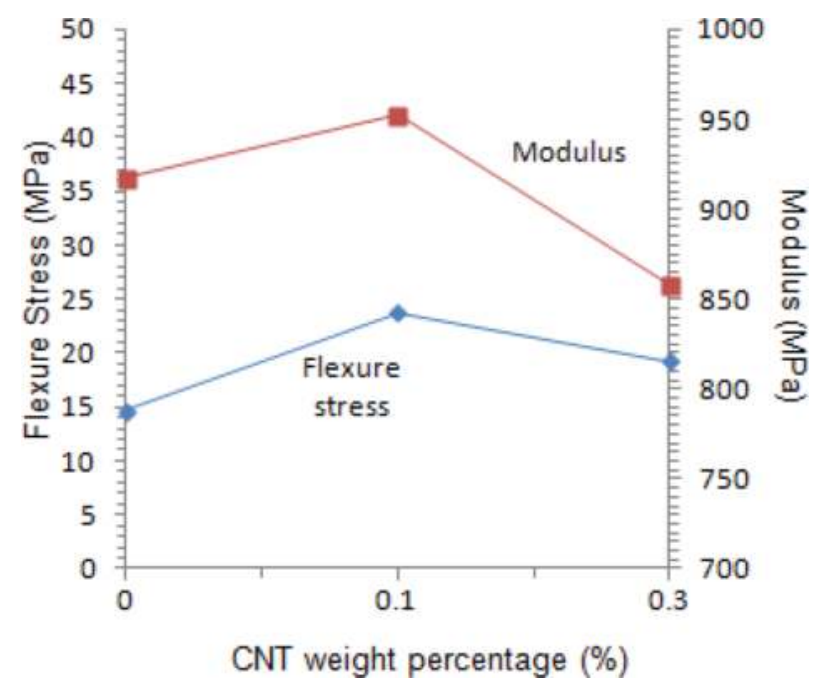

Figure 2. Effect of CNTs content on flexural strength and modulus. 


\begin{tabular}{lll}
\hline Load, $\mathbf{P}(\mathbf{N})$ & Stress intensity factor, $\mathbf{K}_{\mathrm{IC}}\left(\mathbf{M p a . m}^{1 / 2}\right)$ & Increase in $\mathbf{K}_{\mathrm{IC}}(\%)$ \\
\hline 175.915 & 1.10 & 0.00 \\
285.392 & 1.79 & 62.7 \\
& & \\
231.268 & 1.45 & 31.8 \\
\hline
\end{tabular}

Table 2. Fracture toughness of epoxy system.

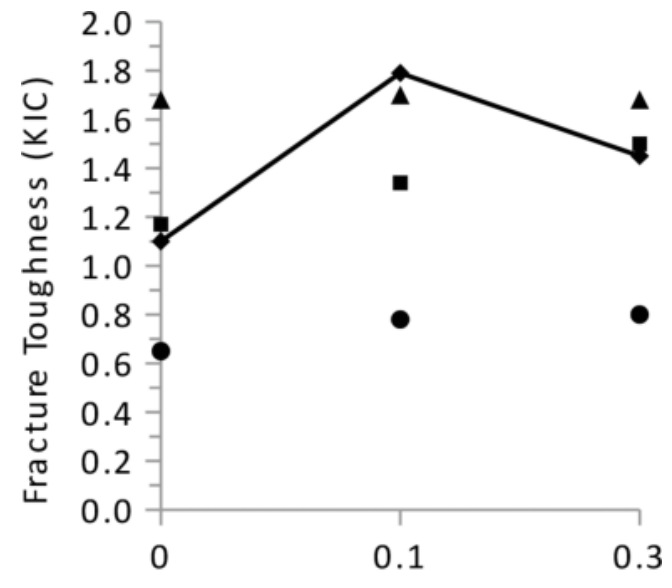

\section{CNT weight percentage (wt\%)}

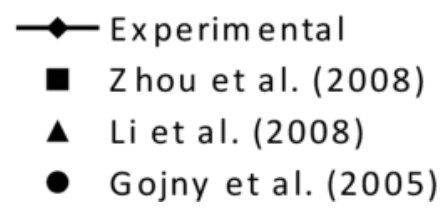

Figure 3. Effect of CNTs content on fracture toughness.

Figure 4 shows SEM images of the fracture surfaces of neat epoxy and MWNTs reinforced composites. Figure 4a shows a fractography feature of neat epoxy. The distance between two cleavage steps is about $2.64-7.84 \mu \mathrm{m}$, and the cleavage plane between them is flat and featureless. Figures $4 \mathbf{b}$ and $3 \mathrm{c}$ show the fracture surface of composites with MWNTs inclusion. The fracture surfaces of the nanocomposites show a different fractographic features. The surface roughness increased with higher CNTs content. Figure $4 \mathrm{~b}$ and $4 \mathrm{c}$ also indicates that the size of the cleavage plane decreased with higher CNTs content. The SEM picture in Figure $4 \mathrm{c}$ shows that the size of the cleavage plane decreased to $0.77-2.74 \mu \mathrm{m}$ after the infusion of the $0.3 \mathrm{wt} \%$ CNTs.

According to Zhou et al. [12] and Srivasta and Singh [13], the decrease of cleavage plane and the increase of surface roughness were correspond to the number of isolated and dispersed 


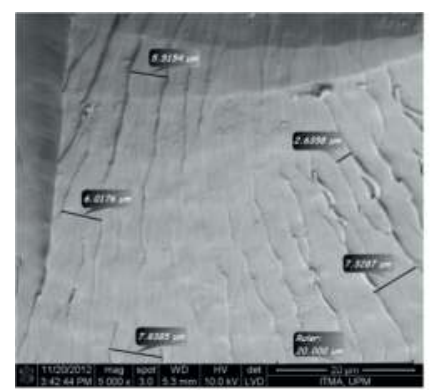

(a)

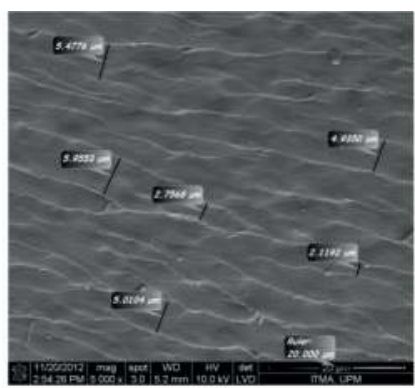

(b)

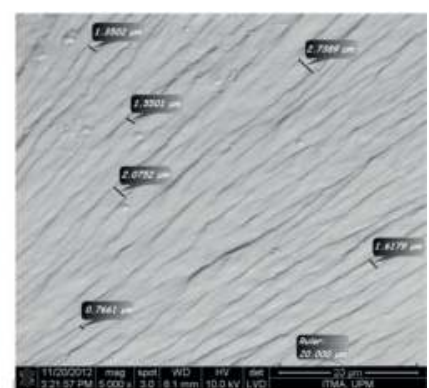

(c)

Figure 4. Cleavage plane at 5000X magnification of (a) neat epoxy, (b) epoxy with $0.1 \mathrm{wt} \%$ MWNTs, and (c) epoxy with $0.3 \mathrm{wt} \%$ MWNTs.

MWNTs, which force the crack to propagate, bypassing the MWNTs and distorted the crack tip. This phenomenon indicates that the good adhesion has taken place between MWNTs and epoxy resin and fractured in different planes. The cracks were spanned by the MWNTs causing enhanced resistance to the crack propagation process. Here, MWNTs have played a role for pinning crack and carry the external force. They have created a firm connection and good interaction with the matrix. Therefore, the MWNTs have prevented the expansion of microcracks resulted from the stress concentration and thus improved the toughness of the composites. Also, some deep cleavages are seen in both neat and modified epoxy surfaces but in modified epoxy, instead of deep cleavage, the crack tip is more bifurcate and also leads to a rough surface features. The bifurcation mechanism probably has caused a dissipation of more fracture energy throughout the failure process, promotes plastic deformation and leads to the improvement of toughness and ductility [16]. Here, MWNTs have played a role of crack path deflection.

In this experiment, the fracture toughness of epoxy with $0.3 \mathrm{wt} \%$ MWNTs content was lower than $0.1 \mathrm{wt} \%$ MWNTs. A possible explanation can be given for this behaviour is the not-well dispersion state in $0.3 \mathrm{wt} \%$ MWNTs. This condition was in agreement with the work reported by Gkikas et al. [14], where at constant processing of sonication power and time, the degree of dispersion of less CNT concentration (0.1 wt\% MWNTs) is higher than the higher concentration (0.3 wt \% MWNTs). Also, samples with lower CNT concentration exhibited larger modulus than samples with higher concentration. This is because at higher contents of CNTs inclusion, the amount of aggregated particles is higher; thus, the processing power and time should be increased to ensure a good state of dispersion within the matrix. Aggregated particles usually do not have the load bearing ability as individual particles and they may act as defects [14]. Therefore, the state of dispersion is crucial to the extent the strengthening effect of CNT particles as the concentration becomes larger. This means that to the extent of improvement at higher CNTs content, the processing parameters play a key important role to improve the dispersion state.

The presence of a partly agglomerated dispersion of MWNTs that found in epoxy with $0.3 \mathrm{wt} \%$ MWNTs can be seen in Figure 5. The agglomeration in turn leads to the localized 


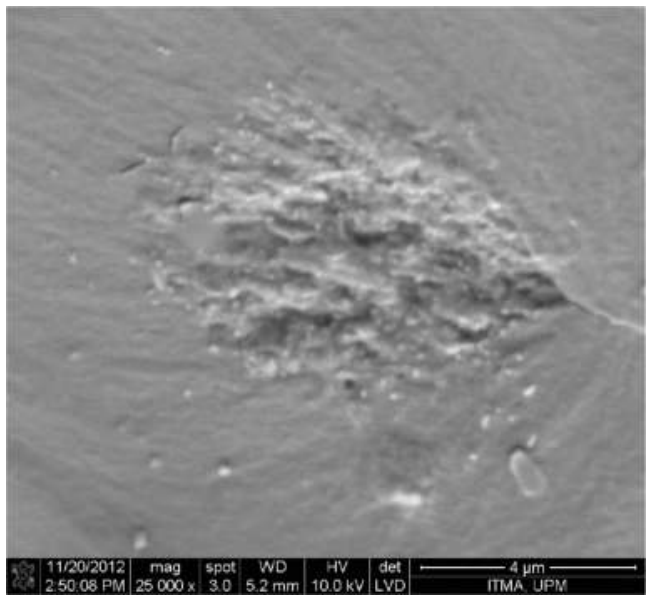

Figure 5. Agglomeration at $0.3 \mathrm{wt} \%$ MWNTs-epoxy.

inelastic matrix deformation and void nucleation. The localized deformation converted the elastic strain energy to surface energy [8]. When the epoxy resin is subjected to mode I loading, shear stress is generated between the CNTs wall and the surrounding matrix resin due to the difference in their elastic properties [17]. If they are well bonded, CNTs are deformed together with the matrix. However, if the mode I loading exceeded to some critical value that leads to debonding of CNTs from the matrix, the CNTs will stop elongating together with the matrix and a further increase of the load applied can only result in the deformation of the matrix. Thus, the polymer starts to flow over the surface of CNTs, and deformation energy will be dissipated through the slippage between the CNTs and matrix [17]. Other related explanation by Greef et al. [18] is that CNTs have a high stiffness in comparison with the epoxy, and their presence creates an abrupt stiffness variation in the matrix. Therefore, this stiffness mismatch introduces local disturbances in the stress distribution around the CNTs and establishing a weak link to the material and increases the number of potentials for the material to have such a weak link. Thus, multiple "weak" sites are identified, and they compete with each other for becoming a crack path. Some of these sites fail earlier which made the sample fail quickly as occurred in $0.3 \mathrm{wt} \%$ MWNTs content. But, if they are not part of a larger chain, they do not grow into larger cracks and remain isolated (Figure 6).

However, in the authors' opinion, this experiment has not yet been fully answered all the possible toughening mechanism occurred in the polymer matrix. There are further mechanisms participate in the toughening process which can be seen through other method than FESEM. Based on those uncertainties enhancement and unpredicted void existence, it is believed that there are such mechanisms lead to stress relation in the materials and decrease the stress intensity at the crack front which consumes energy rather than increasing the total fracture surface area which cannot be seen through FESEM (Wetzel [19]). As a whole, former researchers proposed that energy absorption by crack bridging and fibre pull-out of CNTs 


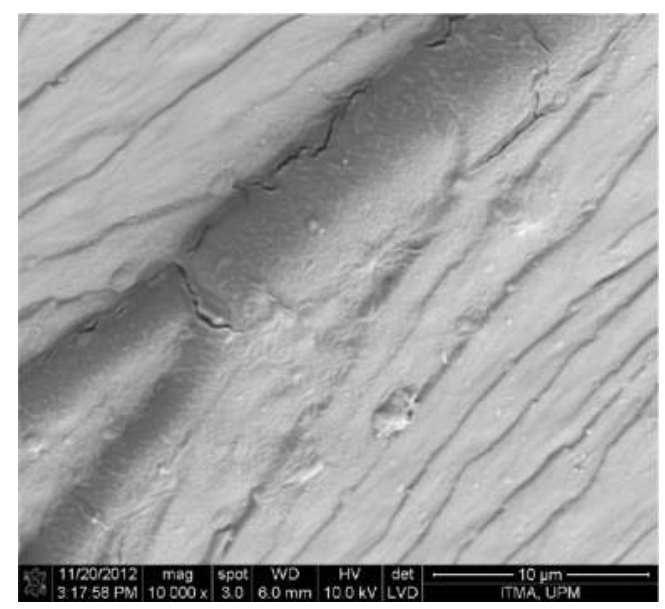

Figure 6. Isolated microcracks found at $0.3 \mathrm{wt} \%$ MWNTs.

was responsible for the major increase in fracture toughness. But according to this research work, we found that crack pinning, crack path deflection, localized inelastic plastic deformation and void nucleation mechanisms were the most attribute toughening mechanism in CNTs' modified epoxy.

\section{Conclusions}

CNTs are qualified for the toughening of the higher viscosity epoxy resin for aircraft application because they are able to enhance damage tolerance of the composite structure. The key important factor for significant enhancement is achieving the optimum state of dispersion and interfacial adhesion by manipulating and controlling the processing method. Welldispersed MWNTs can easily alleviate the stress concentration of the matrix and eliminate the adverse effect of voids. In this study, the flexural strength and the fracture toughness at the break were clearly improved with CNTs additives. The increase of performance is because $\mathrm{CNTs}$ resist the matrix deformation through several toughening mechanisms. No crack bridging mechanism by MWNTs is observed in present study, and no obvious CNTs are detected on the fracture surface during microscopic analysis. However, a more thorough study on the evaluation of surfaces is necessary, and the toughening mechanisms should be further investigated in future works.

\section{Acknowledgements}

The authors would like to gratefully acknowledge the support of Fundamental Research Grant Scheme (FRGS) of the Ministry of Higher Education. 


\section{Author details}

Aidy Ali*, Risby M. Sohaimi and Ahmad H. Muhammad Ismail

*Address all correspondence to: saidynaidy@gmail.com

Department of Mechanical Engineering, Faculty of Engineering, Universiti Pertahanan

Nasional Malaysia, National Defense University of Malaysia, Kuala Lumpur, Malaysia

\section{References}

[1] Rassiah K, Megat Ahmad MMH, Ali Aidy, Sihombing H. 3-D cartesian method in characterisating of mechanical properties of bamboo polyester composite. Advances in Environmental Biology. 2014;8(8):2632-2639

[2] Rassiah K, MMH MA, Ali Aidy. Mechanical properties of laminated bamboo strips from gigantochloa scortechinii/ polyester composite. Materials and Design. 2014;57:551-559

[3] Rassiah K, MMH MA, Ali Aidy, Tamizi MM. The influence of laminated layer and thickness gigantochloa scortechinii bamboo strips on mechanical performance of unsaturated polyester composites. Life Science Journal. 2015;12(2):182-188

[4] Rassiah K, MMH MA, Ali Aidy. Ballistic impact performance of the layered and laminated composites: A review. Pertanika Journal of Science and Technology. 2015;23(2): 177-185

[5] Rassiah K, Megat Ahmad MMH, Ali Aidy, Abdullah AH, Nagapan S. Mechanical properties of layered laminated woven bamboo Gigantochloa scortechinii/epoxy composites. Journal of Polymer and Environment Springer. 2017:1-15

[6] Ali Aidy, Rassiah K, Othman F, Pueh LH, Earn TT, Hazin MS, Ahmad MMHM. Fatigue and fracture properties of laminated bamboo strips from Gigantochloa scortechinii / polyester composites. BioResources. 2016;11(4):9142-9153

[7] Ali Aidy, Ng WK, Arifin F, Rassiah K, Othman F, Hazin MS, Megat Ahmad MMH. Development and mechanical characterization of green bamboo composites. AIP Conference Proceedings. 2 February 2018;1930. Article ID: 020012. DOI: 10.1063/1.5022906

[8] Gojny FH, Winchmann MHG, Fiedler B, Schulte K. Influence of different on mechanical properties of epoxy matrix. Composites Science and Technology. 2005;65:2300-2313

[9] Harris PJF. Carbon nanotube composites. International Materials Reviews. 2004:49

[10] Thostenson ET, Chou T-W. Processing structure multifunctional property relationship in carbon nanotube/epoxy composites. Carbon. 2006;44:3022-3029

[11] Yu N, Zhang ZH, He SY. Fracture toughness and fatigue life of MWCNT/epoxy composites. Materials Science and Engineering. 2008;494:380-384 
[12] Zhou Y, Pervin F, lewis l, Jelani S. Fabrication and characteristic of carbon/epoxy composites mixed with Multiwalled carbon nanotubes. Materials Science and Engineering A. 2008;475:157-165

[13] Srivasta VK, Singh S. A micro-mechanical model for elastic modulus of multi-walled carbon nanotube/epoxy resin composite. International Journal of Composite Materials. 2012;2(2):1-6

[14] Gkikas G, Barkoula N-M, Paipetis AS. Effect of dispersion conditions on the thermomechanical and toughness properties of multi walled carbon nanotubes- reinforced epoxy. Composites Part B Engineering. 2012;43:2679-2705

[15] LI Y, Shimizu H. High-shear processing induced homogenous dispersion of pristine Multiwalled carbon nanotubes in a thermoplastic elastomer. Polymer. 2007;48:2203-2207

[16] Ayatollahi MR, Shadlon S, Shokrieh MM. Mixed-mode brittle fracture in epoxy/ multi-walled carbon nanotube nanocomposites. Engineering Fracture Mechanics. 2011;78:2620-2632

[17] Ma P-C, Siddiqui NA, Marom G, Kim J-Y. Dispersion and functionalization of carbon nanotubes for polymer-based nanocomposites: A review. Composites: Part A. 2010;41:1345-1367

[18] Greef ND, Gorbatikh 1, Gandra A, Mezzo 1, lomov SV, Verpoest I. The effect of carbon nanotubes on the damage development in carbon fiber/epoxy composites. Carbon. 2011;49:4650-4664

[19] Wetzel B, Rosso P, Haupert F, Friedrich K. Epoxy nanocomposite - Fracture and toughening mechanisms. Engineering Fracture Mechanics. 2006;73:2375-2398 